\title{
PENGARUH BENTUK KAMPUH TERHADAP KARAKTERISTIK BAJA KARBON RENDAH HASIL PENGELASAN SMAW
}

\author{
Ferry Budhi Susetyo, Agus Dudung, Supria Wiganda, Ahdian Haris, Wahyu \\ Nugroho \\ Jurusan Teknik Mesin, Fakultas Teknik, Universitas Negeri Jakarta \\ e-mail : fbudhi@unj.ac.id
}

\begin{abstract}
ABSTRAK
Penelitian ini bertujuan untuk mengetahui pengaruh bentuk kampuh terhadap cacat dan kekuatan tarik material baja karbon rendah hasil pengelasan SMAW dengan elektroda AWS E. 7018. Jenis kampuh las yang digunakan adalah kampuh $V$ dan $X$, penyiapan bahan dengan menggunakan mesin scrap. Variasi arus yang digunakan adalah 140,150, 160 dan 170 A dengan polaritas DC + .

Proses pengelasan dilakukan di laboratorium las Teknik Mesin Universitas Negeri Jakarta, kemudian proses pengujian radiografi di PT. Gamma Hepsi dan proses pengujian tarik dilakukan di B2TKS Puspitek. Dari kedua hasil pengujian tersebut dilakukan analisa supaya didapatkan kesimpulan.

Kesimpulan yang dapat ditarik dari hasil penelitian ini adalah: Hasil pengelasan SMAW dengan arus 140 A, 150 A, 160 A dan 170 A yang menggunakan kampuh X mendapatkan nilai tegangan tarik ratarata yang lebih rendah terhadap spesimen yang menggunakan kampuh $V$ dengan selisih tegangan tarik ratarata sebesar $35,14 \mathrm{~N} / \mathrm{mm}^{2}$. Hal ini terjadi karena pengelasan dengan kampuh $X$ mengalami proses pengelasan di dua sisi pada waktu yang berbeda. Hal ini menyebabkan pada spesimen kampuh X memiliki tegangan tarik terendah karena adanya tegangan sisa yang besar.
\end{abstract}

Kata Kunci : ST. 42, E.7018, SMAW, Uji Tarik

\section{PENDAHULUAN}

Dewasa ini penggunaan pengelasan dalam konstruksi sangat luas dipergunakan dalam penyambungan batang-batang pada konstruksi bangunan dan konstruksi mesin, meliputi perkapalan, jembatan, rangka baja, pipa saluran dan lain sebagainya. Karena konstruksi bangunan dan konstruksi mesin tidak semuanya dapat di cetak melalui proses casting, maka hal ini dapat di lakukan melalui proses ikatan metalurgi pada sambungan logam atau logam paduan yang dilaksanakan dalam keadaan lumer atau cair, berdasarkan definisi las dari Deutche Industrie Normen (DIN).

Pemilihan sambungan las atau kampuh mempengaruhi efisiensi pengerjaan, efisiensi sambungan dan kekuatan sambungan pada konstruksi las yang mempunyai dampak terhadap kekuatan dari hasil pengelasan. Pada dasarnya pemilihan sambungan las atau kampuh harus menuju pada penurunan panas dan penurunan logam las sampai pada batas terendah yang tidak menurunkan kekuatan sambungan. Oleh karena itu pemilihan sambungan las atau kampuh harus sesuai dengan spesifikasi logam yang akan di las.

Elektroda E. 7018 termasuk salah satu elektroda berjenis low hydrogen atau hidrogen rendah. Elektroda ini membutuhkan penanganan khusus sebelum menggunakan elektroda tersebut. Elektroda low hydrogen harus dikeringkan secara benar agar tidak berkurangnya kekuatan sambungan las.

Pada penelitian ini penentuan besar arus dalam pengelasan mengambil $140 \mathrm{~A}, 150 \mathrm{~A}, 160$ A, dan 170 A. Pengambilan arus 140 A dimaksudkan sebagai batas arus terendah dan 170 A sebagai batas arus tertinggi. Berdasarkan permasalahan yang dipaparkan di atas, maka tujuan dari penelitian ini adalah untuk mengetahui jenis cacat-cacat yang terjadi serta kekuatan tarik dari variasi kampuh. 


\section{TINJAUAN PUSTAKA}

\subsection{Hakikat Las}

Berdasarkan definisi dari Deutche Industrie Norman (DIN) las adalah ikatan metalurgi pada sambungan logam atau paduan logam yang dilaksanakan dalam keadaaan lumer atau mencair [Harsono, 1981]. Dari definisi tersebut dapat juga di artikan sambungan antara dua logam atau lebih melalui energi panas.

Pengelasan berdasarkan cara kerjanya dapat diklasifikasikan menjadi tiga kelompok yaitu pengelasan cair, pengelasan dengan tekanan dan pematrian. Dalam penggunaannya pengelasan yang sering digunakan adalah pengelasan cair dengan busur listrik atau gas. Pengelasan cair dapat diartikan yaitu suatu proses pengelasan dengan cara memberikan perlakuan panas terhadap benda yang akan disambung hingga mencair dengan menggunakan sumber energi listrik. Las listrik dapat dibagi menjadi 4 jenis yaitu las busur dengan elektroda terbungkus, las busur gas ( TIG, MIG, las busur $\mathrm{CO}_{2}$ ), las busur tanpa gas, las rendam. Salah satu dari jenis las busur elektroda terbungkus adalah las SMAW (Shielded Metal Arc Welding)[Hery Sunaryo, 2008].

Las SMAW (Shielded Metal Arc Welding) adalah suatu proses pengelasan dengan busur listrik yang mana penggabungan atau perpaduan logam diberikan perlakuan panas yang dihasilkan dari busur listrik yang dikeluarkan diantara elektroda terbungkus dan permukaan logam dasar yang di las. Elektroda yang digunakan berupa kawat yang dibungkus oleh pelindung fluks. Elektroda ini selama pengelasan akan mengalami pencairan bersama dengan logam induk dan membeku bersama menjadi bagian kampuh las. Proses pemindahan logam elektroda terjadi pada saat ujung elektroda mencair dan membentuk butirbutir yang terbawa arus busur listrik yang terjadi. Bila digunakan arus listrik besar maka butiran logam cair yang terbawa menjadi halus dan sebaliknya bila arus kecil maka butirannya menjadi besar.

Pola pemindahan logam cair sangat mempengaruhi sifat mampu las dari logam. Logam mempunyai sifat mampu las yang tinggi bila pemindahan terjadi dengan butiran yang halus. Pola pemindahan cairan dipengaruhi oleh besar kecilnya arus dan komposisi dari bahan fluks yang digunakan. Bahan fluks yang digunakan untuk membungkus elektroda selama pengelasan mencair dan membentuk terak yang menutupi logam cair yang terkumpul di tempat sambungan dan bekerja sebagai penghalang oksidasi.

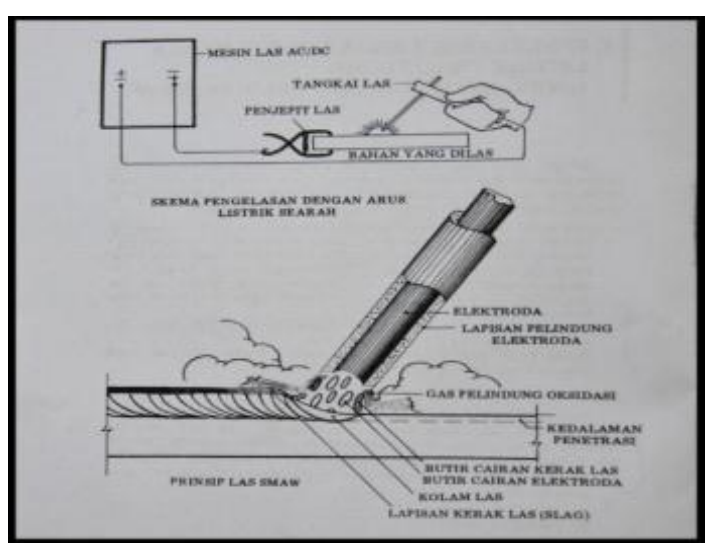

Gambar 2.1 Skema Pengelasan SMAW [Sri Widharto, 2008]

\subsection{Mesin Las SMAW}

Mesin las merupakan sumber tenaga yang memberi jenis tenaga listrik yang diperlukan serta tegangan yang cukup untuk terus melangsungkan proses pengelasan.

Sumber tenaga mesin las dapat diperoleh dari

- Motor bensin atau diesel

- Gardu induk

Tegangan pada mesin las listrik biasanya :

- 110 volt

- 220 volt

- 380 volt

Antara jaringan dengan mesin las pada bengkel terdapat saklar pemutus. Mesin las digerakkan dengan motor, cocok untuk pekerjaan lapangan atau pada bengkel yang tidak mempunyai jaringan listrik. Busur nyala terjadi apabila dibuat jarak tertentu antara elektroda dengan benda kerja dan kabel massa dijepitkan ke benda kerja.

Mesin las SMAW dibagi menjadi tiga macam, yaitu mesin las arus bolak-balik (AC), 
mesin las arus searah (DC) dan mesin las arus ganda yang merupakan mesin las yang dapat digunakan untuk pengelasan arus bolak-balik (AC) dan arus searah (DC).

\subsection{Polaritas}

Mesin las DC dapat digunakan dengan dua cara yaitu polaritas langsung dan polaritas terbalik. Pada polaritas langsung, kabel elektoda dipasang pada terminal negatif dan kabel masa pada terminal positif. Polaritas langsung sering disebut sebagai sirkuit las listrik dengan elektroda negatif (DC-).

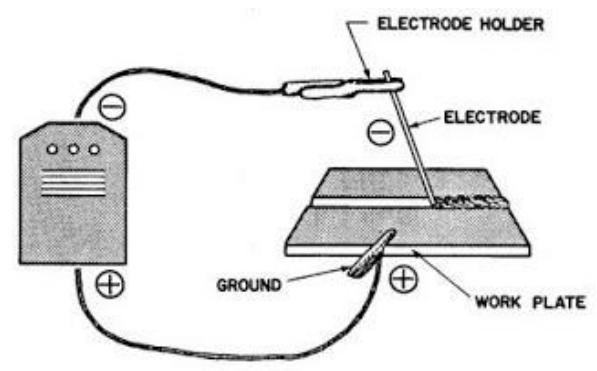

Gambar 2. 2. Polaritas Negatif (DC-)

Untuk polaritas terbalik, kabel elektroda dipasang pada terminal positif dan kabel masa dipasang pada terminal negatif. Polaritas terbalik sering disebut sirkuit las listrik dengan elektroda positif (DC+).

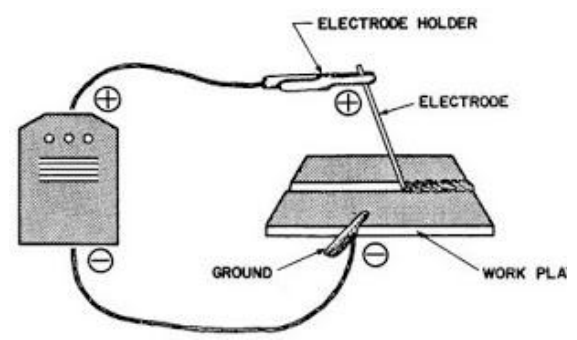

Gambar 2. 3. Polaritas Positif (DC+)

\section{4 Kampuh Las}

Alur pengelasan dinyatakan oleh sepasang sisi ujung dari dua logam yang akan disambung dengan pengelasan. Persiapan kampuh las meliputi persiapan ujung-ujung permukaan. Sebuah kampuh las harus dirancang untuk pengelasan yang efisien secara ekonomis dan mudah pelaksanaannya dan untuk meminimalkan jumlah endapan tanpa menyebabkan cacat las. Ubah bentuk geometri kampuh, sesuaikan dengan ketebalan logam yang akan disambung : kampuh I, V, X, U atau $\mathrm{H}$ harus dipilih sesuai penambahan ketebalan.

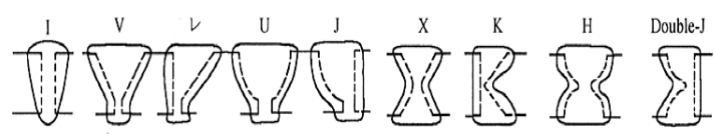

Gambar 2.4 Bentuk Geometri Kampuh.

Kampuh las dapat dipersiapkan dengan pemesinan atau pemotongan panas lainnya. Metode pemotongan panas yang dapat dipakai meliputi : pemotongan gas, pemotongan busur plasma, pemotongan busur udara, pemotongan laser, dsb. Yang paling umum dilakukan adalah metode pemotongan gas. Jika kampuh dipersiapkan dengan menggunakan pemotongan gas atau pemotongan busur plasma, serpihan serpihan kotoran pada permukaan harus dibuang. Karena permukaan yang dipotong secara kasar pada permukaan kampuh dapat menyebabkan cacat las, maka hal-hal tersebut harus diperbaiki dengan penggerindaan atau dengan metodemetode lain yang tepat.

\subsection{Tipe Elektroda AWS E. 7018}

Jenis Elektroda E.7018 adalah jenis hidrogen rendah, dapat dipakai mengelas dalam semua posisi dan mengandung $25-40 \%$ serbuk besi yang dapat dipakai pada mesin las AC dan DC. Untuk mengelas pada jenis-jenis yang sukar dilas seperti Baja belerang tinggi, Baja karbon tinggi dan baja paduan rendah. Pada umumnya kawat las ini jenis low hydrogen, pengelasan harus dikendalikan pada jarak busur yang pendek dan las sudut dibawah tangan akan menghasilkan bentuk sedikit cembung dengan rigi-rigi halus gelombang yang bagus. Kawat las jenis E. 7018 sebagai kawat las yang halus, busur nyala terang, penembusan dangkal, sangat sedikit menimbulkan percikan dan dapat dipakai dengan kecepatan gerak tinggi.

Bahan salutan kawat las ini termasuk jenis kapur (line feritic) mengandung serbuk besi, setelah di las terak mudah dibersihkan, kawat salutan dibuat lebih tebal dibandingkan kawat las lainnya. Dan kawat las AWS E. 7018 harus dioven bila dipakai mengelas dengan kadar air yang banyak untuk menghindari cacat pengelasan. 
Kalsifikasi Elektroda berdasarkan AWS pada umumnya setiap negara yang memproduksi Elektroda mencantumkan klasifikasi sendiri juga mencantumkan kode AWS, Contoh AWS E. 7018

\section{AWS : American Welding Society}

E: Elektroda ( Elektroda Untuk Las Listrik)

Angka 70: 70.000 Psi tegangan tarik dari kawat las

Angka ke 3 (1) : adalah menunjukkan posisi las

Angka ke 4 (8) : adalah menunjukkan

Jenis Salutan

Jenis Polaritas mesin Las

Tipe penembusan

Kandungan persen (\%) serbuk besi. Artinya : Kekuatan tarik minimum dengan deposit las adalah 70.000 Psi dan dipakai untuk pengelasan segala posisi.

Tabel 2. 1. Tipe Elektroda 7018 [Sunari, 2007]

\begin{tabular}{c|c|c|c|}
\multicolumn{2}{c|}{ Diameter Kawat Las } & Arus Las & Tegangan Busur \\
\hline Inci & $\mathrm{mm}$ & (Ampere) & (Volt) \\
\hline $3 / 32$ & 2,50 & $70-125$ & $17-21$ \\
$1 / 8$ & 3,25 & $150-165$ & $18-22$ \\
$5 / 32$ & 4,00 & $150-220$ & $20-24$ \\
$3 / 16$ & 5,00 & $200-275$ & $21-25$ \\
$7 / 32$ & 5,50 & $260-340$ & $22-26$ \\
$1 / 4$ & 6,00 & $315-400$ & $23-27$ \\
$5 / 16$ & 8,00 & $375-470$ & $23-28$
\end{tabular}

\section{6. Jenis Cacat Las [Sriwidharto, 2009]}

Cacat las merupakan salah satu dari faktor kegagalan pengelasan,jenisjenisnya dapat dikelompokan dalam tiga golongan, yakni:

Cacat permukaan yang visual, seperti: surface spatter, highlow, surface porosity, pin hole, surface crack (longitudinal,transversal, crater/star, toe, crack, surface undercut(low stress dan high stress), excessive surface reinforcement, wide bead, weaving fault, stop start, surface lap, surface concavity.

Cacat permukaan nonvisual (cacat pada akar las) yakni: root porosity, root undercut, rootcrack, blow hole/burn through, suck back, incomplete penetration (IP), root concavity, excessive root reinforcement/penetration.
Cacat internal (cacat didalam material las atau bahan induk disekitar las), yakni : slag inclusion, slag lines, internal porosity, worm hole/piping, incomplete fusion (IF), heavy metal inclusion, cold lap, underbead crack, internal crack(longitudinal, transversal), hollow bead.

\section{METODOLOGI PENELITIAN}

Alur kerja penelitian adalah gambaran umum untuk memandu peneliti dalam melakukan penelitian. Alur kerja yang akan dilakukan adalah sebagai berikut :

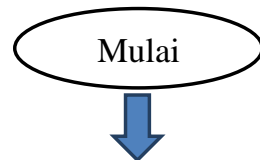

Mengunpulkan data dan literatur

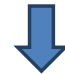

Persiapan bahan, spesimen las dan alat

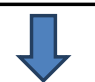

Pengelasan dengan variasi arus

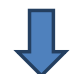

Pengujian Spesimen dengan Uji Radiografi

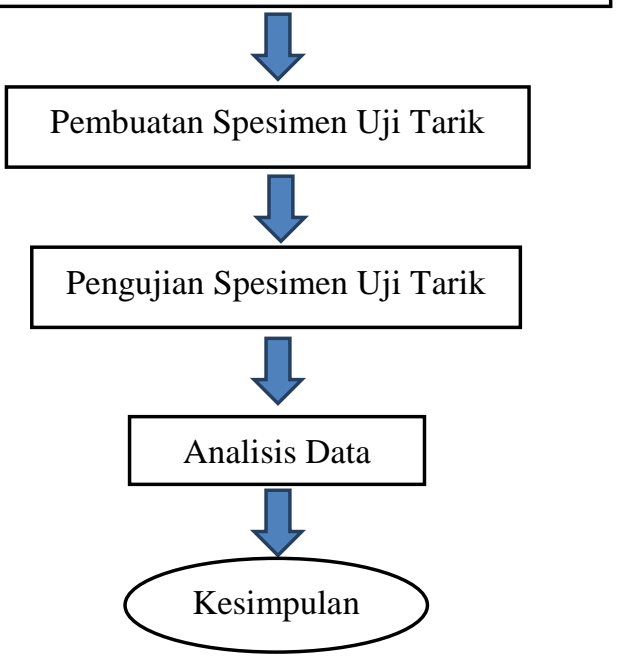

Gambar 3.1 Alur Proses Penelitian 


\section{HASIL DAN PEMBAHASAN}

\section{a. Hasil Uji Radiografi.}

Dari data hasil uji radiografi terdapat tiga jenis cacat las yang terjadi, yaitu cacat las slug inclusi, porosity dan inclusi penetration. Pada spesimen yang menggunakan kampuh $\mathrm{V}$ dengan arus 140 A dan pada spesimen yang menggunakan kampuh $\mathrm{X}$ dengan arus 140 A terjadi cacat las slug inclusi. Sementara pada spesimen yang menggunakan kampuh $\mathrm{X}$ dengan arus 140 A, 150 A, 160 A dan 170 terjadi cacat las porosity. Dan cacat las inclusi porosity terjadi pada spesimen yang menggunakan kampuh $\mathrm{V}$ dengan arus 150 A, 160 A, dan 170 A dan pada spesimen yang menggunakan kampuh $\mathrm{X}$ dengan arus $140 \mathrm{~A}$.

\section{b. Hasil Uji Tarik.}

Pengujian tarik dilakukan untuk mengetahui kekuatan tarik maksimum pada masing - masing spesimen yang ada dalam penelitian ini. Hasil pengujian tarik pada umumnya adalah penggunaan tegangan tarik maksimum. Data dari hasil pengujian tarik specimen yang menggunakan kampuh $\mathrm{V}$ dan kampuh $\mathrm{X}$ dapat dilihat pada tabel berikut ini:

Tabel 4.1 Tabel Hasil Uji Tarik

\begin{tabular}{|c|c|c|c|c|}
\hline $\begin{array}{l}\mathrm{N} \\
\mathrm{o}\end{array}$ & $\begin{array}{c}\text { Spesim } \\
\text { en }\end{array}$ & $\begin{array}{c}\text { Teganga } \\
n \\
\text { Maksim } \\
\text { um } \\
\left(\mathrm{N} / \mathrm{mm}^{2}\right)\end{array}$ & $\begin{array}{c}\text { Rata }- \\
\text { rata } \\
(\mathrm{N} / \mathrm{mm} \\
2 \\
2)\end{array}$ & $\begin{array}{c}\text { Kamp } \\
\text { uh }\end{array}$ \\
\hline \multirow[t]{3}{*}{1} & \multirow{3}{*}{$\begin{array}{c}\text { Baja } \\
\text { Tanpa } \\
\text { Las }\end{array}$} & 433,21 & \multirow[t]{3}{*}{408,86} & \multirow[t]{3}{*}{ - } \\
\hline & & 385,17 & & \\
\hline & & 408,22 & & \\
\hline \multirow{6}{*}{2} & \multirow{6}{*}{$\begin{array}{c}\text { Hasil } \\
\text { Lasan } \\
\text { Arus } \\
140 \mathrm{~A}\end{array}$} & 442,75 & \multirow[t]{3}{*}{451,05} & \multirow[t]{3}{*}{ V } \\
\hline & & 457,60 & & \\
\hline & & 452,81 & & \\
\hline & & 399,29 & \multirow[t]{3}{*}{413,7} & \multirow[t]{3}{*}{$\mathrm{X}$} \\
\hline & & 418,57 & & \\
\hline & & 423,25 & & \\
\hline \multirow{6}{*}{3} & \multirow{6}{*}{$\begin{array}{c}\text { Hasil } \\
\text { Lasan } \\
\text { Arus } \\
150 \mathrm{~A}\end{array}$} & 477,90 & \multirow[t]{3}{*}{442,9} & \multirow[t]{3}{*}{$\mathrm{V}$} \\
\hline & & 432,98 & & \\
\hline & & 447,79 & & \\
\hline & & 413,45 & \multirow[t]{3}{*}{415,24} & \multirow[t]{3}{*}{$X$} \\
\hline & & 404,21 & & \\
\hline & & 428,07 & & \\
\hline & & 450,09 & \multirow[t]{2}{*}{453,1} & \multirow[t]{2}{*}{ V } \\
\hline & & 462,44 & & \\
\hline
\end{tabular}

\begin{tabular}{|c|c|c|c|c|}
\hline 4 & Hasil & 446,78 & & \\
\cline { 3 - 3 } & Lasan & 399,29 & 417,6 & $\mathrm{X}$ \\
& Arus & 430,10 & & \\
& $160 \mathrm{~A}$ & 423,42 & & \\
\hline & & 444,98 & 461,8 & $\mathrm{~V}$ \\
5 & & 465,95 & & \\
& Hasil & 474,58 & & \\
& Lasan & 403,64 & 421,76 & $\mathrm{X}$ \\
& Arus & 433,92 & & \\
& $170 \mathrm{~A}$ & 427,72 & & \\
\cline { 3 - 3 } & & & & \\
\hline
\end{tabular}

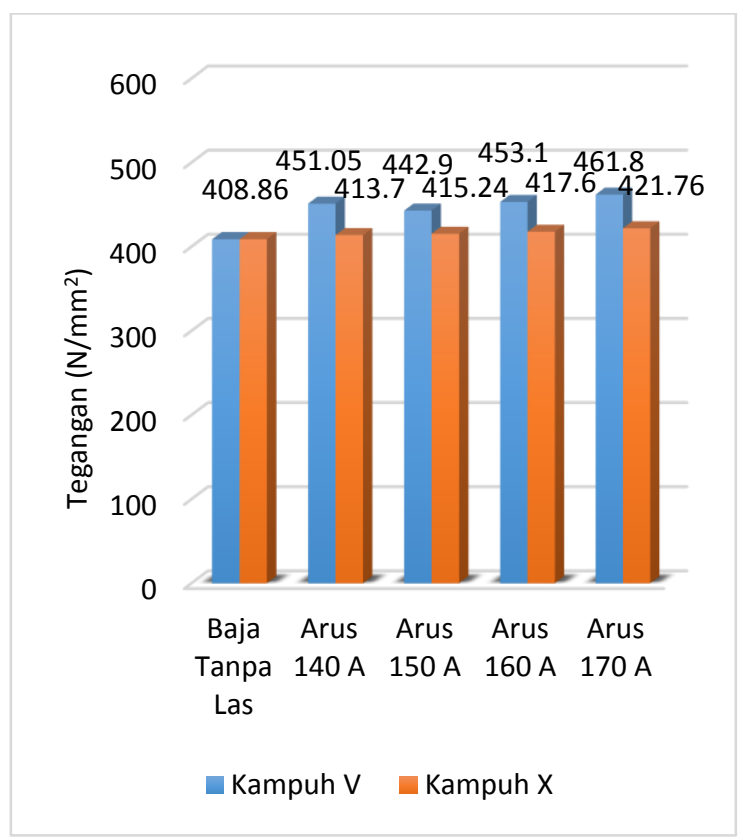

Gambar 4.1 Diagram tegangan tarik maksimum rata - rata, hasil pengelasan SMAW kampuh V dan kampuh $\mathrm{X}$

Pada hasil uji tarik dari gambar 4.1 spesimen baja tanpa las mendapatkan tegangan tarik maksimum rata - rata 408,86 kN. Hasil pengelasan dengan menggunakan kampuh $\mathrm{V}$ mendapatkan nilai rata - rata tegangan tarik maksimum terendah sebesar $442,9 \mathrm{k} / \mathrm{N}$ pada arus 150 A dan nilai rata - rata tegangan tarik maksimum tertinggi sebesar $461,8 \mathrm{k} / \mathrm{N}$ pada arus 170 A. Sedangkan pada hasil pengelasan yang menggunakan kampuh $\mathrm{X}$ mendapatkan nilai rata rata tegangan tarik terendah sebesar $413,7 \mathrm{k} / \mathrm{N}$ pada arus 140 A dan mendapatkan nilai rata - rata tegangan tarik maksimum tertinggi sebesar $421,76 \mathrm{k} / \mathrm{N}$ pada arus $170 \mathrm{~A}$. 


\section{KESIMPULAN}

Berdasarkan hasil penelitian, didapatkan kesimpulan sebagai berikut:

1. Terjadi cacat las slug inclusi pada spesimen yang menggunakan kampuh $\mathrm{V}$ dengan arus 140 A dan pada spesimen yang menggunakan kampuh $\mathrm{x}$ dengan arus $140 \mathrm{~A}$.

2. Terjadi cacat las porosity pada spesimen yang menggunakan kampuh X dengan arus $140 \mathrm{~A}, 150$ A, 160 A dan 170 A.

3. Terjadi cacat las inclusi porosity pada spesimen yang menggunakan kampuh $\mathrm{V}$ dengan arus $150 \mathrm{~A}, 160$ A, dan 170 A dan pada spesimen yang menggunakan kampuh $\mathrm{X}$ dengan arus $140 \mathrm{~A}$.

4. Hasil pengelasan SMAW dengan arus $140 \mathrm{~A}, 150 \mathrm{~A}, 160 \mathrm{~A}$ dan $170 \mathrm{~A}$, yang menggunakan kampuh $\mathrm{X}$ mendapatkan nilai tegangan tarik rata-rata yang lebih rendah terhadap spesimen yang menggunakan kampuh $\mathrm{V}$ dengan selisih tegangan tarik rata-rata sebesar $35,14 \mathrm{~N} / \mathrm{mm}^{2}$.

\section{REFERENSI}

[1] Amstead, B. H. dkk, 1997 Teknologi Mekanik, Jakarta: Erlangga.

[2] American welding society, 1993. Specification for Underwater Welding, Miami: AWS

[3] Daryanto, 2010. Proses Pengolahan Besi dan Baja (Ilmu Metalurgi), Bandung: sarana Tutorial Nurani Sejahtera.

[4] Direktorat Pendidikan Menengah Kejuruan, 2004. Tingkat Lanjut Dengan Proses Gas Metal, Yogyakarta: Direktorat Pendidikan Menengah Kejuruan

[5] Sonawan, Hery dan Suratman, Rochim. 2006. Pengantar Untuk Memahami Proses Pengelasan Logam, Bandung: Alfabeta.
[6] Sunari. 2007. Teknik pngelasan Logam, Jakarta: Ganeca Exact.

[7] Sunaryo, Hery. 2008. Teknik Pengelasan Kapal jilid 1,Jakarta: Direktorat Pembinaan Sekolah Kejuruan.

[8] Sunaryo, Hery. 2008. Teknik Pengelasan Kapal jilid 2,Jakarta: Direktorat Pembinaan Sekolah Kejuruan.

[9] Sunggono, Kh. 1995. Buku Teknik Sipil. Bandung: Nova

[10] Surdia, Tata dan Saito, Shinroku. 1999. Pengetahuan Bahan Teknik, Jakarta: Pradnya Paramita.

[11] Widharto, Sri. 2009 Inspeksi Teknik Buku 1, Jakarta: Pradnya Paramita.

[12] Widharto, Sri. 2009 Inspeksi Teknik Buku 3, Jakarta: Pradnya Paramita.

[13] Widahrto, Sri. 2008 Petunjuk Kerja Las, Jakarta: Pradnya Paramita.

[14] Wiryosumarto, Harsono dan Okumura, Toshie. 1981. Teknologi Pengelasan Logam, Jakarta: Pradnya Paramita. 